\title{
https://doi.org/10.46813/2021-134-166 STREAMER MODE OF POSITIVE CORONA
}

\author{
O.V. Bolotov, B.B. Kadolin, S.M. Mankovskyi, V.M. Ostroushko, I.A. Pashchenko, \\ G.V. Taran, L.M. Zavada \\ National Science Center “Kharkov Institute of Physics and Technology”, Kharkiv, Ukraine \\ E-mail: ostroushko-v@kipt.kharkov.ua
}

One cycle of quasi-periodic streamer mode of positive corona at constant voltage is considered. The calculation results for the streamer propagation at a voltage near to threshold of the streamer mode and for the stage of partial release of the gap from the ions are presented. The simplified model of ionization development near the anode before the start of the next streamer is considered and it is estimated the ionized space size, from which the streamer propagation begins.

PACS: $52.80 . \mathrm{Hc}$

\section{INTRODUCTION}

The positive corona in the streamer mode is used in plasma chemical devices, in particular in ozonizers. Under the constant voltage application, there is a quasiperiodic process, each cycle of which consists of the formation of plasma space near the needle-anode, the propagation of such space in the discharge gap (in other words, the propagation of the cathode directed streamer), with a significant increase in total current when the plasma space leading edge approaches the cathode, and the subsequent decay of ionization processes, with drift, diffusion, recombination of charged particles and formation of conditions for the next streamer start. Experimental research and numerical simulations of streamers have been performed in many works (in particular, [1 - 3]), and attention was paid, mainly, to the propagation of one streamer through the discharge gap. In the experiments with a large distance between the electrodes and the large applied voltage, the formation of a large number of streamers was observed, which is why in a number of works the numerical simulations of the simultaneous propagation of two streamers were performed to study interaction of streamers. A detailed review of research on the physics of streamers is presented in [4]. Plasma chemical devices use a relatively low voltage, the value of which may be near to one corresponding to the lower threshold of the streamer mode. If the voltage increases then the frequency of streamers formation increases, leading, in particular, to gas heating. At a sufficiently high voltage, there is a spark breakdown of the discharge gap.

When modeling the quasi-stationary streamer propagation in the discharge gap [5 - 7], gas heating can be ignored, because during the propagation of one streamer the gas heating is small. Even at the values of the applied voltage, slightly higher than the upper threshold of the streamer mode, when the gap overlapping by the first streamer leads to spark formation, the characteristics obtained in the calculations without gas heating corresponds (to some extent) to the characteristics of the first streamer. And at voltage values only slightly above the lower threshold of the streamer mode, the sensitivity of some characteristics (for example, the time interval between the propagation of consecutive streamers through the gap and the streamers propagation velocity) to the voltage value is relatively high, but the spatial distribution of the process development is quite similar to that observed at somewhat higher voltage values. And here it should be noted that the unusual distributions of electron and positive ion densities, field strength and potential near the streamer head, which were obtained in simulations of the quasi-stationary streamer propagation for a voltage near to the lower threshold of the streamer mode in [7], are the result of wrong direction of positive ions motion, through the error in the calculation program. Some details of those distributions are a reflection of the non-stationary quasiperiodic process that arose in those calculations and was described in [6] and [7]. In the calculations carried out after the appropriate changes in the program, the mentioned process disappeared.

In the present work, the main attention is paid to the part of one cycle of the quasi-periodic streamer mode, which covers the process of the channel destruction and the formation of conditions for the new streamer start. The streamer propagation in the gap of about $1 \mathrm{~cm}$ width requires a time of about $10^{-7} \mathrm{~s}$, whereas the typical time interval between the pulses in the streamer mode is about $10^{-4} \mathrm{~s}$, and therefore numerical simulation of multiple formation and propagation of the streamer with the same care, with which the simulation of just the stage of the streamer propagation is usually performed would take much more time, therefore, to simulate the channel destruction and the formation of conditions for the new streamer start, it is advisable to perform calculations on relatively coarse meshes and to use the simplified models. Section 1 presents the results of calculations of the quasi-stationary streamer propagation at low voltage excess over the value corresponding to the lower threshold of the streamer mode. The results for the process of the streamer channel destruction and partial release of the gap from ions during the time interval between the propagation of consecutive streamers are given in Section 2. In Section 3 the simplified model is considered, which describes the evolution of charged particle distribution near the anode before the next streamer start.

\section{PROPAGATION AT VOLTAGE NEAR TO THRESHOLD OF STREAMER MODE}

At the beginning, if a time of the voltage increase to its stationary value is much less than characteristic time of streamer development then characteristics of streamer 
propagation correspond to the mentioned stationary value. But if the voltage increases slowly then the first streamer starts at the voltage value corresponding to the lower threshold of streamer mode in the given experimental conditions. With a further voltage increase, the time between the consecutive streamers decreases, as under the action of a stronger average field the ion removal from the gap and formation of the conditions for the next streamer start goes faster. With average field strength increase, the transverse (to the direction of propagation) streamer size and the streamer propagation velocity increase, as with a larger size of the streamer head the field strength has the same value at a greater distance from the head, and the avalanche development there during the same time leads to a greater streamer propagation velocity.
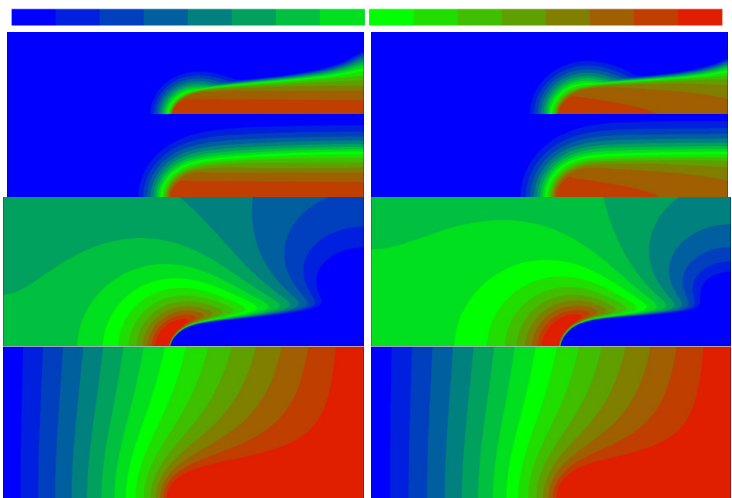

Fig. 1. Distributions of electron and positive ion densities, electric field strength, and potential at the average field strength near the cut-off, for gas parameters, corresponding to $\mathrm{N}_{2}$ (left) and $\mathrm{O}_{2}$ (right). The scale (16 colors at the top) is logarithmic for densities, $10^{9} \ldots 10^{15} \mathrm{~cm}^{-3}$, and strength, $10^{4} \ldots 10^{6} \mathrm{~V} / \mathrm{cm}$, and linear for potential, $0 \ldots 3800 \mathrm{~V}$ and $0 \ldots 4800 \mathrm{~V}$, for $\mathrm{N}_{2}$ and $\mathrm{O}_{2}$, respectively. The values outside the intervals are shown in the same color as the nearest values

If the average field strength is not very near to its value corresponding to the lower threshold of streamer mode then the streamer propagation velocity is much greater even than that drift velocity, which the ions have in the strong field near the streamer head. Therefore, the simulations of streamer propagation are often performed under the assumption that the ions are immobilized. The need to take into account the ion motion arises at the average field strength very near to the threshold, when the streamer propagation velocity is low. As it is mentioned in the introduction, in the program used in [5 - 7] for the simulations of quasi-stationary streamer propagation, through the error, the direction of positive ions motion was wrong, which, at the average field strength value near to the threshold, led to non-stationary quasiperiodic high-frequency propagation mode, described in [6] and [7], and at a slightly higher average strength value gave the distribution of the charged particle densities, field strength and potential presented in [7]. The corresponding distributions obtained in the simulations of quasi-stationary streamer propagation carried out after the appropriate changes in the program, are shown in Fig. 1.
The calculations for the charged particle distributions in the coordinate system connected with a streamer begin from some initial distributions usually taken from the results of the calculations at another, near value of the average strength, and therefore, the initial distributions differ from that to be obtained in the result of calculations. In the performed calculations, at an average strength value near to the threshold, relaxation was slow and it was accompanied by oscillations of the streamer propagation characteristics, but the quasi-periodic mode with transverse ionization wave described in [6] and [7] was not observed.

\section{CHANNEL EVOLUTION AFTER DISCHARGE GAP OVERLAPPING}

At the time of the discharge gap overlapping by a streamer, a significant part of the streamer channel is the plasma near to quasi-neutral one, with a density of electrons and positive ions of the order of $10^{14} \mathrm{~cm}^{-3}$. Due to attachment, the channel also contains negative ions, which density, at the beginning, is much lower, but it increases with time. Due to ion-ion recombination, negative ions play a significant role in reducing the density of positive ions during the channel destruction. The main source of electron supply to the channel is ionelectron emission from the cathode. When this supply decreases, there are enough electrons (together with negative ions) to compensate the positive charge nearer to the channel axis, and the uncompensated outer layer of positive ions expands in the direction perpendicular to the axis under the action of mutual repulsion of the layer parts. The action of the axial component of the positive charge field slows down the electron motion to the anode most strongly in the channel part nearer to the anode, with the increase of the three-body attachment and ion-ion recombination rates there. This effect, in combination with the positive ion drift in cathode direction, accelerates the positive ion density decrease in the part of the streamer channel nearer to anode. By turn, the higher density of positive ions nearer to cathode enhances ion-ion recombination there, which, in combination with the negative ion drift in anode direction, accelerates the negative ion density decrease in the part of the streamer channel nearer to cathode. Negative ion can release electron, absorbing photon with energy greater than the electron binding energy (which is much less than the ionization energy), and so, negative ions are an additional source of seed electrons for the development of electron avalanches, during the streamer propagation [8]. Therefore, before the next streamer start, a negative ion distribution is formed that is less conducive to the propagation of the next streamer in the part of the gap slightly nearer to the cathode than to the anode, which leads to some decrease of total current during the propagation of the next streamer in the mentioned part of the gap and to formation of two maxima in the total current time dependence, during the next streamer propagation.

In Fig. 2 it is shows a typical sample of the calculation results for evolution of some characteristics of the channel destruction, during the time interval from 0.2 to $10 \mu$ s after the streamer start. The values 0 and 1 on the 
$y$-axis correspond to the minimum and maximum values of the respective quantities in the mentioned interval. For the values normalized in this way, the sequence of quantities whose time dependences intersect, in ascending order, the vertical line (not drawn) related to the time $4 \mu \mathrm{s}$ is as follows: 1) average electron coordinate; 2) positive ion number; 3 ) electron number; 4) total current; 5) ionization frequency; 6) attachment frequency; 7) negative ion number; 8) average ionization coordinate; 9) average positive ion coordinate; 10) average attachment coordinate; 11) average negative ion coordinate. Here, the 'number' means the total number of corresponding charged particles in the calculation volume, the 'frequency' is the number of acts of the corresponding reaction in the calculation volume per time, the 'coordinate' is the distance from the cathode, the curves numbered 2-5 are very near to each other.

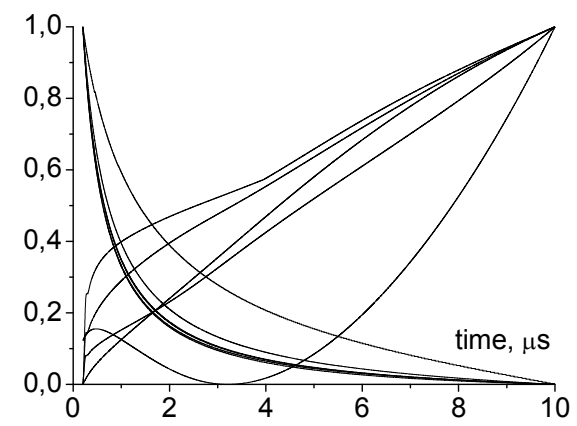

Fig. 2. Time evolution of some characteristics during the stage of streamer channel destruction (in text)

The obtained dependence of the average coordinates on time shows an increase, with time (at this stage of a streamer mode cycle), of the ionization and attachment rates in the gap part nearer to the anode.

\section{FORMATION OF CONDITIONS FOR THE NEXT STREAMER START}

During the channel destruction, the charge of positive ions becomes the main part of the charge of the channel residues. The drift of these positive ions in the cathode direction leads to the field strengthening near the needle-anode and to the corresponding increase in the ionization intensity. It is advisable to consider a relatively simple model to describe the process near the anode before the next streamer start.

The field distribution near the anode roughly corresponds to the field distribution near the perfectly conductive paraboloid of revolution, where the product of the field strength at the symmetry axis with the distance from the focus is a constant. In the considered model, it is neglected by attachment and assumed that the ionization coefficient $\alpha$ is connected with the field strength $E$ by the equality $\alpha=\tilde{\alpha}(E)$, in which $\tilde{\alpha}(E)=\alpha_{\mathrm{a}} \exp \left(-E_{\mathrm{a}} / E\right), \alpha_{\mathrm{a}}$ and $E_{\mathrm{a}}$ are constants, and the field strength distribution along the direction to the cathode is given by an equality $E=V / r$, where $r$ is the distance from a certain point inside the anode, $V$ is a constant. Then the electron multiplication from the density $n_{\mathrm{e} 0}$ (at an infinitely distant point) gives, at the point with coordinate $r$, the density $n_{\mathrm{e}}$, for which $\ln \left(n_{\mathrm{e}} / n_{\mathrm{e} 0}\right)=\int_{r}^{\infty} d r^{\prime} \tilde{\alpha}\left(V / r^{\prime}\right)$, and so,

$$
n_{\mathrm{e}}=n_{\mathrm{e} 0} \exp \left[\tilde{\alpha}(V / r) V / E_{\mathrm{a}}\right] .
$$

At the stage when ionization at the given point, with a constant value of the field strength, is carried out by electrons with constant density coming from the points farther from the anode, for the rate of positive ion density increase at the point $r$, neglecting the motion of ions, one comes to the equation

$$
d n_{\mathrm{p}} / d t=\tilde{v}(E) n_{\mathrm{e}},
$$

where $\tilde{v}(E)=\mu_{\mathrm{e}} E \tilde{\alpha}(E), \mu_{\mathrm{e}}$ is electron mobility (assumed independent of the field strength below).

But the space charge field strengthening, due to the increase in the positive ion density, leads to the formation of a well-conducting quasi-neutral medium, with relaxation of the field strength, similar to the relaxation of stresses in elastic-viscous materials (Maxwell relaxation). At the stage when the plasma is near to quasineutral one, with an electron density near to the positive ion density, the time evolution of field strength is determined by the equation

$$
d E / d t=-E e_{0} \mu_{\mathrm{e}} n_{\mathrm{p}} / \varepsilon_{0},
$$

where $\varepsilon_{0}$ is electric constant, $e_{0}$ is elementary charge.

The equations (2) and (3) are related to the different stages in the evolution of particle density and field distributions near the anode. These stages are separated by the time interval, during which the field strength at the given point changes significantly, but so that the ionization remains quite intense, and the density of positive ions is still significantly different from its final value. However, to obtain estimates on the order of magnitude, one may consider the equations (2) and (3) as a system of equations. For its solution one gets

$$
n_{\mathrm{p} 0}^{2}-n_{\mathrm{p}}^{2}=2 n_{\mathrm{e}}^{2} \mathrm{E}_{2}\left(E_{\mathrm{a}} / E\right) E t_{\mathrm{e}} /\left(E_{\mathrm{a}} t_{\mathrm{a}}\right) .
$$

Here $\mathrm{E}_{m}(x)=\int_{1}^{\infty} d \tau e^{-\tau x} / \tau^{m} \quad(m=1,2,3, \ldots)$ (the integral exponent, which obeys the asymptotic relation $\mathrm{E}_{m}(x) \sim e^{-x} / x$, at $\left.x>>1\right), t_{\mathrm{e}}=\varepsilon_{0} /\left(e_{0} \mu_{\mathrm{e}} n_{\mathrm{e}}\right)$ (a characteristic relaxation time for the field in a quasi-neutral plasma with a density $\left.n_{\mathrm{e}}\right), t_{\mathrm{a}}=1 /\left(\alpha_{\mathrm{a}} \mu_{\mathrm{e}} E_{\mathrm{a}}\right)$ (the multiplied by $\exp (-1)$ characteristic time between the successive ionizations carried out by one electron in a field with strength $E_{\mathrm{a}}$ ), $n_{\mathrm{p} 0}$ is the final (for $t \rightarrow \infty$ ) value of $n_{\mathrm{p}}$. If at the beginning of the considered ionization process development it is held the relation $n_{\mathrm{p} 0}-n_{\mathrm{p}} \sim n_{\mathrm{p} 0}$ then the relations,

$$
\begin{gathered}
p_{0} \sim \varepsilon \exp [-1 /(2 \varepsilon)]\left(t_{\mathrm{e}} / t_{\mathrm{a}}\right)^{1 / 2}, \\
t_{\mathrm{p}}=t_{\mathrm{e}} / p_{0} \sim\left(t_{\mathrm{e}} t_{\mathrm{a}}\right)^{1 / 2} \exp [1 /(2 \varepsilon)] / \varepsilon,
\end{gathered}
$$

with $p_{0}=n_{\mathrm{p} 0} / n_{\mathrm{e}}, \varepsilon=E / E_{\mathrm{a}}, t_{\mathrm{p}}=\varepsilon_{0} /\left(e_{0} \mu_{\mathrm{e}} n_{\mathrm{p} 0}\right)$ (a characteristic time of the field relaxation at the end of the process), take place. And according to the equation (2), for the time $t_{0}$, necessary to reach the value $n_{\mathrm{p} 0}$ of the ion density, from the initial zero value, at the ionization rate corresponding to the initial (before relaxation) field strength, one comes to the relations

$$
t_{0} \sim p_{0} \exp (1 / \varepsilon) t_{\mathrm{a}} / \varepsilon \sim\left(t_{\mathrm{e}} t_{\mathrm{a}}\right)^{1 / 2} \exp [1 /(2 \varepsilon)] \sim \varepsilon t_{\mathrm{p}} .
$$

In particular, for the initial field strength of the order of $E_{\mathrm{a}}(\varepsilon \sim 1)$ one has $t_{0} \sim t_{\mathrm{p}}$. And for $\varepsilon<<1$, in con- 
nection with the relation $t_{0} \sim \varepsilon t_{\mathrm{p}}$, for the total time, $t_{\mathrm{t}}$, of the ionization process development, one gets $t_{\mathrm{t}} \sim t_{\mathrm{p}}$, and therefore, taking into account (4) and (1), one comes to the relation

$t_{\mathrm{t}} \sim\left(t_{\mathrm{e} 0} t_{\mathrm{a}}\right)^{1 / 2} \exp \left[\left(r E_{\mathrm{a}}^{2}-\alpha V^{2}\right) /\left(2 V E_{\mathrm{a}}\right)\right] r E_{\mathrm{a}} / V$,

in which $t_{\mathrm{e} 0}=\varepsilon_{0} /\left(e_{0} \mu_{\mathrm{e}} n_{\mathrm{e} 0}\right)$, and the right hand side of which depends on the coordinate $r$ directly and through the dependence $\alpha=\alpha_{\mathrm{a}} \exp \left(-r E_{\mathrm{a}} / V\right)$.

If the field of the formed space charge is weak then the ionization process at the different points goes almost independently, and the derivative $d r / d t_{\mathrm{t}}$ characterizes only the manifestation of the process propagation in space. Taking from (5) the logarithmic derivative with respect to $r$, one gets

$$
\begin{aligned}
& d r / d t_{\mathrm{t}} \sim 2 V \exp \left[\left(\alpha V^{2}-r E_{\mathrm{a}}^{2}\right) /\left(2 V E_{\mathrm{a}}\right)\right] \times \\
\times & \left\{\alpha r E_{\mathrm{a}}\left(t_{\mathrm{e} 0} t_{\mathrm{a}}\right)^{1 / 2}\left[1+(\alpha V)^{-1} E_{\mathrm{a}}+2(\alpha r)^{-1}\right]\right\}^{-1} .
\end{aligned}
$$

If the value of the derivative $d r / d t_{\mathrm{t}}$ (obtained formally from the estimation of time of ionization process development) exceeds the drift velocity of electrons then the estimation contradicts to the used assumption that avalanche multiplication of electrons, which come to the given point from others, takes place in the field, unchanged with time. In fact, under appropriate conditions, the process is rebuilt to the process of propagation of a well-conducting space together with the field formed in front of it, that is, to the process of streamer propagation.

Before the next streamer start there is a slow, somewhat balanced, evolution of ionized space near the anode, namely, the motion to the cathode of positive ions from the channel residues leads to an increase in field strength near the anode and enhancement of ionization there, with the formation of positive ions, the field of which decreases the field strength near the anode and weakens the ionization there. The cause of transition from this evolution to the process of streamer propagation is related to the same mechanism that regulates the transverse size of the streamer during its propagation and is based on some feature of the dependence of the ionization coefficient on the field strength. Namely, a field strength increase at the values somewhat less than a certain value $E_{\mathrm{a}}$ causes a much greater ionization enhancement than that caused by the same field strength increase at the values somewhat greater than $E_{\mathrm{a}}$. With the formation, near the needle-anode, of a wellconducting space within which the field is weak, the distribution of field strength along the cathode direction outside this space can be described by the same dependence $E=V / r$, but with a somewhat different value of $V$ and with such location of the reference point for the coordinate $r$ that at the boundary of well-conducting space it is held the equality $r=r_{\mathrm{b}}$, in which the quantity $r_{\mathrm{b}}$ is near to the radius of curvature of the boundary. Due to the mentioned feature of the dependence of the ionization coefficient on the field strength, the slow propagation of the ionized space, with a sufficiently large radius of curvature of its boundary, becomes unstable with respect to the appearance (due to random, local ionization gain) of the protrusions of the ionized space with some transverse (with respect to the normal to the boundary) size. A field distribution ahead of the protrusion may be assumed similar to the field distribution ahead of the well-conducting space, and it may be described by the dependence $E=V / r$ with the same $V$ and with such location of the reference point for the coordinate $r$ that at the boundary of the protrusion it is held the equality $r=r_{\mathrm{b} 1}$, where $r_{\mathrm{b} 1}$ is the radius of curvature of the protrusion top (this radius is near to half of the protrusion transverse size). The mentioned instability is connected with different forward propagation velocities for the protrusions with different radii of curvature [9]. This velocity is estimated (on the order of magnitude) by the quantity $v_{1}=\tilde{v}\left(V / r_{\mathrm{b} 1}\right) r_{\mathrm{b} 1}$, which corresponds to the ionized space formation during the time $1 / \tilde{v}\left(V / r_{\mathrm{b} 1}\right)$ at the distance $r_{\mathrm{b} 1}$ from its current location. From the equality $v_{1}=\mu_{\mathrm{e}} V \alpha_{\mathrm{a}} \exp \left(-r_{\mathrm{b} 1} E_{\mathrm{a}} / V\right)$, formally, it follows, that the protrusion with less $r_{\mathrm{b} 1}$ propagates ahead faster. However, in reality, at sufficiently large field strength, both electron mobility and ionization coefficient decrease with the strength increase. Moreover, if the radius $r_{\mathrm{b} 1}$ is so small that the product $\tilde{\alpha}\left(V / r_{\mathrm{b} 1}\right) r_{\mathrm{b} 1}$ is less than $20 \ldots 30$ then the continuous medium approximation is far from reality. In any case, there is a certain transverse size of protrusion, for which the protrusion propagation is the fastest, and such protrusion develops into the cathode directed streamer.

The presence of the exponent in the right hand side of the relation (6) allows estimate approximately the argument of the exponent under relatively rough assumptions about values of other quantities included in the relation. In particular, to find out the conditions for the streamer start, assuming that $E \sim E_{\mathrm{a}}, d r / d t_{\mathrm{t}} \sim v_{\mathrm{a}}$, where $v_{\mathrm{a}}=\mu_{\mathrm{e}} E_{\mathrm{a}}$, and looking for $r$ in the assumption that $\alpha r>>1$, one comes to the relations $V \sim r E_{\mathrm{a}}$, $(\alpha V)^{-1} E_{\mathrm{a}}<<1,\left(\alpha V^{2}-r E_{\mathrm{a}}^{2}\right) /\left(V E_{\mathrm{a}}\right) \sim \alpha r-1$,

$$
\alpha r \sim 1+2 \ln \left[\left(t_{\mathrm{e} 0} t_{\mathrm{a}}\right)^{1 / 2} v_{\mathrm{a}} \alpha / 2\right] .
$$

For atmospheric air, where $\left\{\mu_{\mathrm{e}} \sim 400 \mathrm{~cm}^{2} /(\mathrm{V} \cdot \mathrm{s})\right.$, $\left.E_{\mathrm{a}} \sim 250 \mathrm{kV} / \mathrm{cm}, \quad \alpha_{\mathrm{a}} \sim 5 \cdot 10^{3} \mathrm{~cm}^{-1}\right\}, \quad$ one gets $v_{\mathrm{a}} \sim 10^{8} \mathrm{~cm} / \mathrm{s}, \alpha \sim 2 \cdot 10^{3} \mathrm{~cm}^{-1}$. For two different seed electron density values, $n_{\mathrm{e} 0} \sim 10^{6}$ and $n_{\mathrm{e} 0} \sim 10^{3} \mathrm{~cm}^{-3}$, one gets $\left\{\alpha r \sim 18, r \sim 0.9 \cdot 10^{-2} \mathrm{~cm}\right\}$ and $\{\alpha r \sim 24$, $\left.r \sim 1.2 \cdot 10^{-2} \mathrm{~cm}\right\}$, respectively, that is, $r \sim 10^{-2} \mathrm{~cm}$, and $\alpha r>>1$, as it was assumed.

\section{CONCLUSIONS}

Thus, it is considered one cycle of quasi-periodic process, which takes place at constant voltage and consists of the formation of plasma space near the tip of the anode, the propagation of that space in the discharge gap, with a significant increase in total current when approaching its leading edge to the cathode, and subsequent decay of the ionization process, with drift, diffusion, recombination of charged particles, and formation of the conditions for the next streamer start. An evolution of the process characteristics during the stage of the 
channel destruction shows an increase, with time, of the ionization and attachment intensity in the gap part nearer to the anode. The negative ion distribution, with relatively low density nearer to cathode, formed in the discharge gap before the start of the next streamer, promotes formation of two maxima in the total current time dependence, when the next streamer propagates. A simplified model of the development of the ionization process near the anode before the start of the next streamer is considered and the size of the ionized space from which the streamer starts to propagate is estimated.

\section{REFERENCES}

1. O.V. Bolotov, V.I. Golota, B.B. Kadolin, et al. Similarity laws for cathode-directed streamers in gaps with an inhomogeneous field at elevated air pressure // Plasma Physics Reports. 2010, v. 36, № 11, p. 1000-1011.

2. O.V. Manuilenko, V.I. Golota. Computer simulation of positive streamer dynamics in strongly nonuniform electric fields in air. Effect of applied voltage on a streamer velocity for different needle radii // Problems of Atomic Science and Technology. Series "Plasma Physics". 2014, № 6, p. 187-190.

3. O.V. Bolotov, V.I. Golota, S.D. Gurtovoi. Distribution of the gas temperature in streamer discharge in air // Problems of Atomic Science and Technology. Series “Plasma Physics”. 2014, № 6, p. 223-225.
4. S. Nijdam, Ja. Teunissen, U. Ebert. The physics of streamer discharge phenomena // Plasma Sources Sci. Technol. 2020, v. 29, 103001 (49 p).

5. O. Bolotov, B. Kadolin, S. Mankovskyi, V. Ostroushko, I. Pashchenko, G. Taran, L. Zavada. Quasi-stationary streamer propagation // Problems of Atomic Science and Technology. Series "Plasma Electronics and New Methods of Acceleration". 2015, № 4(98), p.185-188.

6. O. Bolotov, B. Kadolin, S. Mankovskyi, et al. Numerical simulations of quasi-stationary streamer propagation // Problems of Atomic Science and Technology. Series "Nuclear Physics Investigations”. 2016, № 5, p. 121-125.

7. O. Bolotov, B. Kadolin, S. Mankovskyi, et al. Numerical simulations of cathode directed streamer propagation in electronegative gases // Problems of Atomic Science and Technology. Series "Plasma Electronics and New Methods of Acceleration". 2018, № 4, p. 172-175.

8. S. Pancheshnyi. Role of electronegative gas admixtures in streamer start, propagation and branching phenomena // Plasma Sources Sci. Technol. 2005, v. 14, p. $645-653$.

9. Yu.P. Raizer, A.N. Simakov. Main factors determining the radius of the head of a long streamer and the maximum electric field near the head // Plasma Physics Reports. 1998, v. 24, № 8, p. 700-706.

Article received 11.06.2021

\section{СТРИМЕРНЫЙ РЕЖИМ ПОЛОЖИТЕЛЬНОЙ КОРОНЫ}

\section{О.В. Болотов, Б.Б. Кадолин, С.Н. Маньковский, В.Н. Остроушко, И.А. Пащенко, Г.В. Таран, Л.М. Завада}

Рассмотрен один цикл квазипериодического стримерного режима положительной короны при постоянном напряжении. Приведены результаты расчетов для распространения стримера при напряжении, близком к порогу стримерного режима, и для стадии частичного освобождения промежутка от ионов. Рассмотрена упрощенная модель развития ионизации вблизи анода перед стартом следующего стримера, и сделана оценка размера ионизованного пространства, от которого начинается распространение стримера.

\section{СТРИМЕРНИЙ РЕЖИМ ПОЗИТИВНОЇ КОРОНИ}

О.В. Болотов, Б.Б. Кадолін, С.М. Маньковський, В.М. Остроуико, І.А. Паценко, Г.В. Таран, Л.М. Завада

Розглянуто один цикл квазіперіодичного стримерного режиму позитивної корони при постійній напрузі. Наведено результати розрахунків для поширення стримера при напрузі, близькій до порогу стримерного режиму, та для стадії часткового звільнення проміжку від іонів. Розглянуто спрощену модель розвитку іонізації поблизу анода перед стартом наступного стримера, та зроблено оцінку розміру іонізованого простору, від якого починається поширення стримера. 